\title{
Determinantes do crédito bancário brasileiro: uma abordagem VAR para o período de 2000 a $2016 *$
}

\author{
Determinants of Brazilian bank credit: a VAR approach for the period 2000 to 2016
}

Vitor Gomes Reginato, Marina Silva da Cunha e Marcos Roberto Vasconcelos**

\begin{abstract}
Resumo: Este trabalho teve como objetivo principal analisar os principais determinantes da concessão de crédito bancário ao setor privado no Brasil, para o período compreendido de 2000 até 2016. Para tanto, foi adotada a metodologia de séries temporais, sendo estimados modelos VAR, bem como os impulsos resposta. Os principais achados empíricos apontam para a influência positiva do PIB e do crédito defasado sobre o volume de operações de crédito. Além desses, depósitos, inflação, juros e do risco Brasil impactam negativamente os empréstimos. Foi possível verificar ainda que o tempo de ajustamento ao choque isolado em cada variável determinante varia, de forma que o impulso nos depósitos se mostrou como o de mais rápido. O risco Brasil, por outro lado, apresentou o mais lento. Por fim, ao se realizar a decomposição do crédito quanto aos seus determinantes foi possível concluir que as variáveis que se mostraram com as maiores parcelas foram o PIB e os depósitos domésticos.
\end{abstract}

Palavras-chave: Crédito Bancário; Modelo VAR; Brasil

Abstract: The main objective of this study was to analyze the main determinants of the Brazilian bank credit concession to private sector for the period from 2000 to 2016. For this purpose, the time series methodology was adopted, with VAR models estimated as well as the impulse responses. The most important empirical findings point to the positive influence of GDP and out of phase credit on the volume of credit operations. Beyond those, deposits, inflation, interest rates and Brazil risk negatively impact loans. It was also possible to verify that the adjustment time for isolated shock in each determinant variable varies, so that the impulse in the deposits was shown the fastest. The Brazil risk, on the other hand, presented the slowest. Finally, when the credit decomposition was carried out with respect to its determinants, it was possible to conclude that the variables that showed the largest shares were GDP and domestic deposits.

Keywords: Bank Credit; VAR Model; Brazil

JEL Code: G21; E44; E51

\footnotetext{
* Submissão: 12/12/2018; aprovação: 01/12/2019. DOI: 10.5380/re.v41i75.63866.

** Respectivamente, doutor em Teoria Econômica pelo PCE/UEM e economista da Secretaria de Economia e Finanças da Prefeitura Municipal de Bauru/SP. E-mail: vitorreginato@bauru.sp.gov.br. ORCID: 00000001-8819-0272. Doutora em Economia Aplicada pela ESALQ/USP e professora Titular do Departamento de Economia da UEM. E-mail: mscunha@uem.br. ORCID: 0000-0001-9122-3944. Doutor em Teoria Econômica pelo IE-UNICAMP e professor Associado do Departamento de Economia da UEM. E-mail: mrvasconcelos@uem.br. ORCID: 0000-0003-1476-4899.
} 


\section{Introdução}

O investimento do setor privado parece se mostrar necessário para promover o crescimento econômico. O financiamento é essencial para que os agentes realizem seus investimentos, dada a restrição de recursos. Assim, tanto para as famílias realizarem seus gastos como para as empresas realizarem suas atividades, o sistema financeiro, em grande parte representado pelos bancos, desempenha um papel crucial, emprestando recursos. Em Schumpeter (1997) ${ }^{1}$, que estudou a dinâmica das economias capitalistas, essa necessidade de empréstimos reside na ideia de estes possibilitarem o processo de inovação que, por sua vez, é o propulsor para o crescimento. Rajan e Zingales (1998) confirmaram empiricamente isso indicando a sensibilidade do desempenho inovador de alguns setores industriais à acessibilidade de crédito junto ao mercado, proxy para o grau de desenvolvimento do sistema financeiro.

Para Levine (1997), um bom funcionamento do mercado financeiro é importante para o crescimento econômico, dado que reduz custos informacionais e melhora a eficiência das transações e da própria alocação dos recursos da economia. Os bancos captam recursos dos agentes credores, na forma de depósitos, e realizam empréstimos aos agentes que desejam se tornar devedores, na forma de operações de crédito. Mas de fato vão além disso, pois transformam as maturidades e condições de liquidez dos diferentes ativos e passivos existentes em uma economia. Nesse processo, diminuem as restrições dos agentes econômicos à geração própria de caixa para viabilizar os gastos em investimentos e inovações, ampliando o potencial de crescimento de longo prazo.

$\mathrm{Na}$ literatura empírica sobre os determinantes do crédito bancário há trabalhos que abordam o lado da demanda, da oferta, ou ambos. Com relação ao lado da demanda estão incluídos Silva e Moraes (2013), Fucidji e Prince (2009), Gimeno e Martinez-Carrascal (2006), Calza et al. (2001 e 2003) e Fase (1995). Por sua vez, do lado da oferta estão Almeida e Divino (2016), Assefa (2014), Imran e Nishat (2013), Frömmel e Schmidt (2006) e Hoffman (2001). Há variáveis que afetam tanto a oferta quanto a demanda por crédito, como observado nos trabalhos de Mendonça e Sachsida (2013), Shijaku e Kalluci (2013), Angeloni et al. (2003) e Kakes (2000).

\footnotetext{
${ }^{1}$ Tradução de Schumpeter, J. A. The theory of economic development. Cambridge, MA: Harvard University Press, 1911.
} 
No Brasil, o volume de operações de crédito exibiu tendência de rápido crescimento ao longo dos anos 2000, chegando ao volume de quase $\mathrm{R} \$ 3$ trilhões em 2016, representando uma parcela de mais de $48 \%$ do PIB, muito acima do apresentado no início da década de 2000, quando essa razão era de 24\%. Já quanto à sua relação com os depósitos domésticos, a mesma lógica é verificada, sendo que em 2016 essa proporção era de mais de $350 \%$, frente aos quase $200 \%$ no início dos anos 2000, mostrando assim a grande representatividade dos empréstimos para a economia.

O objetivo principal deste trabalho consiste em analisar os determinantes do crédito bancário brasileiro independentemente de serem tidos como de oferta ou de demanda de concessão, considerando o período de acentuada expansão dessa variável. Para tanto, é utilizada a metodologia de séries de tempos e foram estimados modelos VAR com os dados mensais do Brasil para o período compreendido de 2000 até 2016.

Assim, o artigo além de abranger para o Brasil um período mais recente do que os trabalhos mencionados, não opta por restringir as estimativas apenas a fatores do lado da oferta ou da demanda do mercado de crédito bancário e leva em consideração todo o estoque de crédito bancário disponibilizado para o setor privado. Mais relevante, o trabalho estima para cada ano analisado a importância das variáveis risco-país (EMBI-Brasil), depósitos bancários, inflação, atividade econômica (PIB) e taxa de juros (SELIC) para a mudança na disponibilidade de crédito bancário. Entre principais resultados encontrados pode ser destacado o peso que os depósitos bancários e o ritmo de atividade econômica tiveram na determinação da evolução do crédito no Brasil ao longo do período analisado. Por sua vez, é marcante como choques que se refletem na elevação do risco-país parecem ter um impacto mais longo e negativo sobre a trajetória do crédito, indicando a sensibilidade desse à incerteza na economia.

Assim, além desta introdução e das considerações finais, este trabalho está dividido em mais quatro seções. Na seção seguinte é realizado um resumo da literatura sobre os determinantes do crédito bancário. $\mathrm{Na}$ sequência são apresentadas as séries históricas consideradas no estudo, bem como o método empregado (seção 3), e exposta uma análise descritiva dos dados (seção 4). Por fim, na quinta seção são discutidos os principais resultados obtidos. 


\section{Crédito bancário: fatos estilizados}

Diversos trabalhos nacionais e internacionais tentam verificar e quantificar quais são os determinantes do crédito bancário e suas principais características nos mais diversos países, utilizando as mais distintas abordagens e métodos. Desta forma, o crédito bancário brasileiro é estudado tanto em trabalhos nacionais quanto internacionais.

Na literatura nacional, Almeida e Divino (2016) objetivaram verificar os determinantes do crédito bancário brasileiro sob a ótica da oferta, estudando as estratégias adotadas pelos bancos e o impacto da política monetária sobre a oferta de crédito. Concluem que há uma inércia no crédito e evidenciam a importância da estratégia dos bancos, sugerindo que maiores ganhos com spread incentivam o aumento da concessão de empréstimos, assim como maiores níveis de despesa com captação, risco de crédito, exigência de capital e um volume maior de Títulos e Valores Mobiliários (TVM) na carteira de ativos do banco tendem a desestimular a oferta de crédito.

Fucidji e Prince (2009) separaram os determinantes do crédito em três diferentes categorias: estratégia dos bancos, política econômica e demanda por crédito. Os resultados apontam para uma relação inversa entre as operações de crédito e as aplicações em títulos públicos e uma correlação positiva com o grau de alavancagem e o PIB. Já Mendonça e Sachsida (2013), ao considerarem a oferta e a demanda de recursos livres, concluíram que a demanda por crédito é pró-cíclica e que a oferta reage positivamente à taxa de juros e negativamente ao custo de captação, taxa de inadimplência e inflação. Silva e Moraes (2013) encontraram resultados semelhantes a estes ao estudarem o crescimento da demanda por crédito no segmento de pessoas físicas em seis estados brasileiros, concluindo que renda afeta positivamente a demanda por crédito, já taxa de juros e desemprego afetam negativamente.

No ambiente internacional, o Brasil é analisado em alguns estudos, como em Guo e Stepanyan (2011) e Harbo Hansen e Sulla (2013), sendo que em ambos os trabalhos o país não é avaliado exclusivamente: no primeiro caso é considerado dentro de um grupo de países em desenvolvimento e, no segundo, dentro dos que constituem a América Latina.

Assefa (2014) e Imran e Nishat (2013) estudaram os determinantes do crescimento do crédito bancário para o setor privado da Etiópia e do Paquistão, 
respectivamente, valendo-se para tanto de uma abordagem da concessão de crédito pelo lado da oferta. Em ambos os trabalhos foi possível verificar que, no longo prazo, crescimento econômico, depósitos domésticos e passivo externo influenciam positivamente a oferta de crédito, sendo que no caso da Etiópia a taxa de juros e a inflação também impactam de forma positiva o volume de empréstimos. Já no segundo trabalho, os autores concluíram ainda que taxa de inflação, bem como taxa de juros não afetam o crédito bancário ao setor privado, assim como os depósitos domésticos no curto prazo.

Em Shijaku e Kalluci (2013) buscou-se identificar para a Albânia os determinantes pelo lado da oferta e da demanda da concessão de crédito bancário ao setor privado, no longo prazo. Foi possível verificar que após a liberalização financeira, a intermediação financeira e bancária, o menor custo dos empréstimos, a redução do endividamento do governo e o crédito bancário com mais qualidade estimularam uma maior demanda por novos empréstimos.

No trabalho de Cottarelli et al. (2003), a análise é feita a partir de um conjunto de 15 países $^{2}$ em desenvolvimento e industrializados, sendo identificada uma relação positiva entre o PIB per capita e os empréstimos, além da inflação acima de determinado valor afetar de forma negativa a concessão de crédito bancário. Os autores concluem ainda que a maior liberalização financeira aumenta a relação crédito-PIB.

Estudando o comportamento dos empréstimos bancários ao setor privado dos países da Zona do Euro, Calza et al. (2001 e 2003) inferem que, no longo prazo, o crescimento do PIB real está positivamente relacionado com o crédito bancário, já as taxas de juros de curto e de longo prazo afetam negativamente. Já Guo e Stepanyan (2011) buscaram verificar os determinantes do crédito para um grupo de 38 economias de mercado emergentes. Os autores encontraram que os depósitos internos, os passivos dos não residentes, o crescimento do PIB e a inflação contribuem positivamente para o crédito bancário, enquanto taxas de juros mais elevadas (representando condição monetária mais restritiva) e política monetária restritiva, por parte dos EUA, afetam negativamente o crescimento do crédito.

\footnotetext{
2 Países do painel: Albânia, Bósnia, Bulgária, Croácia, República Checa, Estônia, Hungria, Letônia, Lituânia, Antiga República Jugoslava da Macedônia, Polônia, Romênia, Sérvia e Montenegro, República Eslovaca e Eslovênia.
} 
Os determinantes da taxa de juros bancária e do crédito bancário para Portugal são estudados em Castro e Santos (2010), sendo que o principal resultado do trabalho foi a relação negativa entre taxa de juros e concessão de crédito, conclusão semelhante à obtida por Hoffman (2001), que considera 16 países industrializados e realiza suas estimativas para o longo prazo.

É possível verificar que diversos trabalhos utilizaram a metodologia de dados em painel para realizar suas estimações, tais como Almeida e Divino (2016), Harbo Hansen e Sulla (2013), Guo e Stepanyan (2011), Fucidji e Prince (2009) e Cottarelli et al (2003). Já Assefa (2014), Imran e Nishat (2013), Shijaku e Kalluci (2013), Castro e Santos (2010), Albulescu (2009) e Fritzer e Reiss (2008) adotaram a abordagem de séries temporais, a mesma adotada no presente estudo.

Ademais, analisando esta revisão da literatura realizada é possível destacar que não há um consenso acerca da influência sobre o crédito bancário de algumas variáveis consideradas como determinantes dos empréstimos bancários, sendo elas inflação e taxa de juros. Por outro lado, as evidências sugerem que, no longo prazo, os depósitos domésticos e o crescimento econômico afetam de forma positiva as concessões de empréstimos em todos os trabalhos verificados.

\section{Metodologia}

\subsection{Dados}

Os determinantes do crédito bancário podem ser classificados como sendo do lado da demanda ou do lado da oferta da concessão. Porém, é difícil distinguir precisamente qual variável afeta cada canal, dado que grande parte das variáveis consideradas na literatura atuam, simultaneamente, na procura e na oferta dos empréstimos. Assim sendo, em nosso estudo não houve essa diferenciação para a realização das estimativas.

Castro e Santos (2010) agruparam em 5 categorias os principais determinantes do crédito privado, baseado em BCE (2007), a saber: (i) variáveis de escala; (ii) variáveis ligadas às condições de financiamento; (iii) variáveis ligadas ao balanço das famílias e das empresas; (iv) fatores relacionados às mudanças estruturais do setor bancário; por fim, (v) outros fatores.

Seguindo Castro e Santos (2010), é possível classificar as variáveis utilizadas neste trabalho da seguinte maneira: PIB como variável de escala; taxa de juros e inflação como variáveis ligadas às condições de financiamento; 
depósitos domésticos como relacionados à categoria de variáveis ligadas ao balanço das famílias e das empresas; e risco Brasil e FED funds rate como outros fatores que são importantes para a determinação dos empréstimos.

As variáveis utilizadas neste trabalho, conforme a Tabela 1, foram extraídas diretamente nos sites do IPEADATA, do Federal Reserve e também do Banco Central do Brasil (Notas Econômico-financeiras para a Imprensa, Política Monetária e Operações de Crédito do SFN; Boletim, Seção Atividade Econômica; Boletim, Seção mercado financeiro e de capitais; Boletim, Seção Balanço de Pagamentos).

Tabela 1 - Descrição das variáveis

\begin{tabular}{lll}
\hline Variável & \multicolumn{1}{c}{ Descrição } & \multicolumn{1}{c}{ Fonte } \\
\hline$C R E D$ & Total de operações de crédito ao setor privado & BACEN \\
$D E P$ & Depósitos à vista + depósitos em poupança & BACEN \\
$I P C A$ & IPCA $(\%$ a.m. $)$ & IPEADATA \\
$P I B$ & Produção em valores correntes & BACEN \\
SELIC & SELIC $(\%$ a.m. $)$ & BACEN \\
$R I S C O$ & Índice EMBI ${ }^{3}$ (fim do período) & IPEADATA \\
$F E D$ & Taxa de juros americana $(\%$ a.a.) & FED \\
\hline
\end{tabular}

Fonte: elaboração própria.

É importante fazer dois comentários. Primeiro, a base de dados apresenta periodicidade mensal, abrangendo o período de janeiro de 2000 até agosto de 2016 e, por fim, vale ressaltar que crédito privado, depósito doméstico e PIB real são apresentados em milhões de reais.

\subsection{Método}

Segundo Greene (2011), é indispensável verificar a estacionariedade ou não de uma série, dado que a utilização de séries não estacionárias pode levar a regressões espúrias, resultando numa relação entre duas variáveis que, na verdade, não existe, gerando conclusões equivocadas. As propriedades de séries temporais

\footnotetext{
${ }^{3}$ Emerging Markets Bond Index Plus (EMBI+) é um índice baseado nos bônus (títulos de dívida) emitidos pelos países emergentes. Mostra os retornos financeiros obtidos a cada dia por uma carteira selecionada de títulos desses países. A unidade de medida é o ponto-base. Dez pontos-base equivalem a um décimo de $1 \%$. Os pontos mostram a diferença entre a taxa de retorno dos títulos de países emergentes e a oferecida por títulos emitidos pelo Tesouro americano.
} 
das variáveis incluídas no modelo são verificadas por meio dos testes de estacionariedade $^{4}$, em que foram utilizados os testes Dickey-Fuller (DF), sua variante aumentada (ADF) e o DF-GLS, os quais possuem como hipótese nula a presença de raiz unitária.

Feitos os testes e verificada a estacionariedade das séries, pode-se partir para a estimativa dos modelos propostos. Aqui, como espera-se que haja uma forte interdependência entre as variáveis selecionadas, é necessário mensurar os vetores autoregressivos que envolvem esta relação de interdependência, os quais descrevem o comportamento de um dado sistema de equações.

Sims (1980) propõe a ideia inicial da técnica de análise Vetor Autoregressivo (VAR), a partir do qual houve grande difusão, se tornando uma das técnicas mais utilizadas nos trabalhos de macroeconomia. Neste modelo, o vetor $\mathbf{y}_{t}$ é formado por um conjunto de variáveis que são dependentes de seus valores defasados e dos valores defasados das demais variáveis consideradas. Dessa forma, todas as variáveis são consideradas como explicativas das demais, sendo assim tidas como endógenas.

O modelo VAR pode ser apresentado, segundo Greene (2011) como:

$$
\mathbf{y}_{t}=\boldsymbol{\Gamma}_{1} \mathbf{y}_{t-1}+\Gamma_{2} \mathbf{y}_{t-2}+\Gamma_{3} \mathbf{y}_{t-3}+\mathbf{v}_{t}
$$

em que $\mathbf{v}_{t}$ representa o vetor de erros com as propriedades de ruído branco.

De acordo com a literatura, o modelo empírico adotado pode ser expresso como:

$$
\begin{gathered}
C R E D=C+\beta_{1} \sum_{j=1}^{k} \operatorname{CRED}_{t-j}+\beta_{2} \sum_{j=1}^{k} D E P_{t-j}+\beta_{3} \sum_{j=1}^{k} P I B_{t-j} \\
+\beta_{4} \sum_{j=1}^{k} S E L I C_{t-j}+\beta_{5} \sum_{j=1}^{k} I P C A_{t-j}+\beta_{6} \sum_{j=1}^{k} R I S C O_{t-j}+\beta_{7} \sum_{j=1}^{k} F E D_{t-j}+\mu_{t}
\end{gathered}
$$

em que:

$C$ é o intercepto;

$\beta_{1}, \beta_{2}, \beta_{3}, \beta_{4}, \beta_{5}, \beta_{6}$ e $\beta_{7}$ são os parâmetros estimados;

$\mu_{t}$ é o erro do modelo.

\footnotetext{
${ }^{4}$ A sequência dos testes utilizada nas séries baseou-se no livro Applied econometric time series, de Enders (2010), ver nota 5 .
} 
A ordem de defasagem das variáveis para o modelo foi escolhida adotando o Critério de Informação de Schwarz, no qual se considera que o modelo não apresenta elevada autocorrelação residual, bem como satisfaz a estabilidade paramétrica. Após realizadas as estimativas, é necessário verificar se todas as raízes se encontram dentro do círculo unitário. Caso alguma raiz do polinômio esteja fora do círculo, o modelo não poderá ser utilizado para realizar análises e previsões, já que se a série sofrer algum choque temporário, este choque será permanente (explosivo). Também é importante fazer testes de autocorrelação dos resíduos. Caso a autocorrelação seja muito forte, o modelo será prejudicado e sua eficácia poderá ser comprometida.

Por fim, foram estimadas as funções de resposta ao impulso, buscando investigar o impacto de um choque a partir dos resíduos sobre as variáveis endógenas. No entanto, deve-se destacar que no trabalho foi utilizado o método básico de estimação do modelo VAR, considerando a chamada "decomposição de Cholesky", que pressupõe uma estrutura recursiva para que o sistema seja identificado. Assim, adota-se uma ordenação causal em que a primeira variável não possa ser afetada contemporaneamente por nenhuma das demais, a segunda possa ser afetada apenas pela primeira, a terceira possa ser afetada pelas duas primeiras e assim por diante. Esta ordenação é relevante para as estimações das funções de resposta ao impulso, uma vez que diferentes ordenações geram diferentes restrições.

No presente trabalho, a ordem adotada manteve a estabelecida na equação 2: Depósitos (DEP), PIB, Taxa Básica de Juros (SELIC), Inflação (IPCA) e Risco Brasil. Em termos mais gerais, tal disposição está alinhada com a hipótese de que as variáveis reais devem ser posicionadas antes das variáveis financeiras, conforme indicam, por exemplo, Lown e Morgan (2006). A premissa é a de que essas se ajustariam rapidamente diante de choques macroeconômicos, representados aqui pela própria efetivação das operações de crédito (CRED), por uma proxy dos fluxos de caixa dos agentes econômicos $(D E P)$ ou o nível de atividade econômica $(P I B)$. A decisão de ordenar a variável $D E P$ antes de $P I B$ assume que parte dos valores da primeira variável é o resultado de decisões passadas dos agentes econômicos e que choques nela observados influenciam o nível de demanda e, por conseguinte, o nível de atividade econômica (PIB) contemporaneamente. Ademais, considerando a vigência do regime de metas de inflação vigente no 
Brasil, assumiu-se que a SELIC não reage contemporaneamente a choques inflacionários, mas que a inflação pode ser contemporaneamente impactada pela política monetária via o efeito de sinalização que a SELIC tem para a formação das expectativas de inflação. ${ }^{5}$

\section{Análise descritiva}

Na Tabela 2, são apresentados os pontos de máximo e de mínimo, a média, a mediana, o desvio padrão e o total de observações, para cada série utilizada. Ao longo dos anos de 2000 até 2016 o volume médio de operações de crédito foi de $\mathrm{R}$ \$ 1,28 trilhão, com seu valor mínimo de $\mathrm{R} \$ 269,82$ bilhões registrado em março de 2000. Os depósitos domésticos apresentaram uma média de $\mathrm{R} \$ 415,18$ bilhões com seu volume máximo em dezembro de 2014 , de pouco mais de $\mathrm{R} \$ \mathbf{8 3 7 , 9 0}$ bilhões. O PIB, que consiste no PIB acumulado dos últimos 12 meses, a valores correntes, atingiu seu valor máximo em agosto de 2016, quando registrou mais de $\mathrm{R}$ \$ 6,17 trilhões, quase o dobro da média histórica registrada, de aproximadamente $\mathrm{R} \$ 3,20$ trilhões.

Tabela 2 - Estatística descritiva das variáveis, 2000-2016

\begin{tabular}{lccccccc}
\hline & $\boldsymbol{C R E D}$ & $\boldsymbol{D E P}$ & $\boldsymbol{P I B}$ & $\boldsymbol{S E L I C}$ & $\boldsymbol{I P C A}$ & $\boldsymbol{R I S C O}$ & $\boldsymbol{F E D}$ \\
\hline Média & $1.279,72$ & 415,18 & $3.203,40$ & 1,09 & 0,55 & 448,44 & 1,88 \\
Mediana & $1.020,82$ & 360,05 & $2.848,76$ & 1,06 & 0,49 & 294,00 & 1,00 \\
Máximo & $2.958,39$ & 837,90 & $6.174,65$ & 2,08 & 3,02 & $2.395,00$ & 6,50 \\
Mínimo & 269,81 & 144,17 & $1.099,35$ & 0,49 & $-0,21$ & 142,00 & 0,25 \\
Desvio-padrão & 917,98 & 229,10 & $1.620,42$ & 0,33 & 0,39 & 369,11 & 2,02 \\
Obs. & 200 & 200 & 200 & 200 & 200 & 200 & 200 \\
\hline
\end{tabular}

Fonte: elaboração própria com dados do Bacen, Ipeadata e FED. Nota: Crédito, Depósito e PIB em bilhões de R\$.

Taxa de juros doméstica, norte-americana e de inflação são apresentadas em valores percentuais. A mais alta inflação mensal foi registrada em novembro de 2002, quando seu valor atingiu 3,02\%, em grande parte explicado pela insegurança no cenário político nacional devido às eleições presidenciais que ocorreram naquele ano. Essa análise pode ainda ser feita analisando o Risco Brasil,

\footnotetext{
${ }^{5}$ Para verificar a sensibilidade dos resultados às escolhas de posicionamento $D E P \Rightarrow P I B$ e $S E L I C \Rightarrow$ inflação, foi testada a ordem alternativa $P I B, D E P$, inflação, taxa básica de juros e Risco Brasil. Os efeitos da função impulso-resposta se mantiveram alinhados com o exposto no ordenamento original.
} 
visto que seu maior valor registrado foi em setembro de 2002, de 2.395 pontos, ilustrando claramente que o mercado estava receoso com relação ao futuro do país. Por sua vez, a SELIC alcançou seu pico apenas em agosto de 2003, atingindo 2,08\%, justificado pela política monetária de metas de inflação adotada, já que a inflação apresentava tendência de elevação.

Na Figura 1 pode ser observada a evolução das operações de crédito ao setor privado e das relações entre as operações de crédito e o PIB e os depósitos domésticos. Na Figura 1a pode ser observado que o saldo de operações de crédito apresentou uma trajetória ascendente ao longo dos anos, passando de pouco mais de $\mathrm{R} \$ 270$ bilhões, em janeiro de 2000, para seu pico de quase R\$ 3 trilhões, em janeiro de 2016, tendência semelhante à observada no painel de 15 países analisado em Cottarelli et al. (2003). Uma das justificativas para tal tendência decorre do cenário econômico otimista apresentado durante este período, o que incentivou as operações de crédito, de acordo com seu caráter pró-cíclico. 
Figura 1 - Operações de crédito, depósitos bancários e PIB, 2000-2016

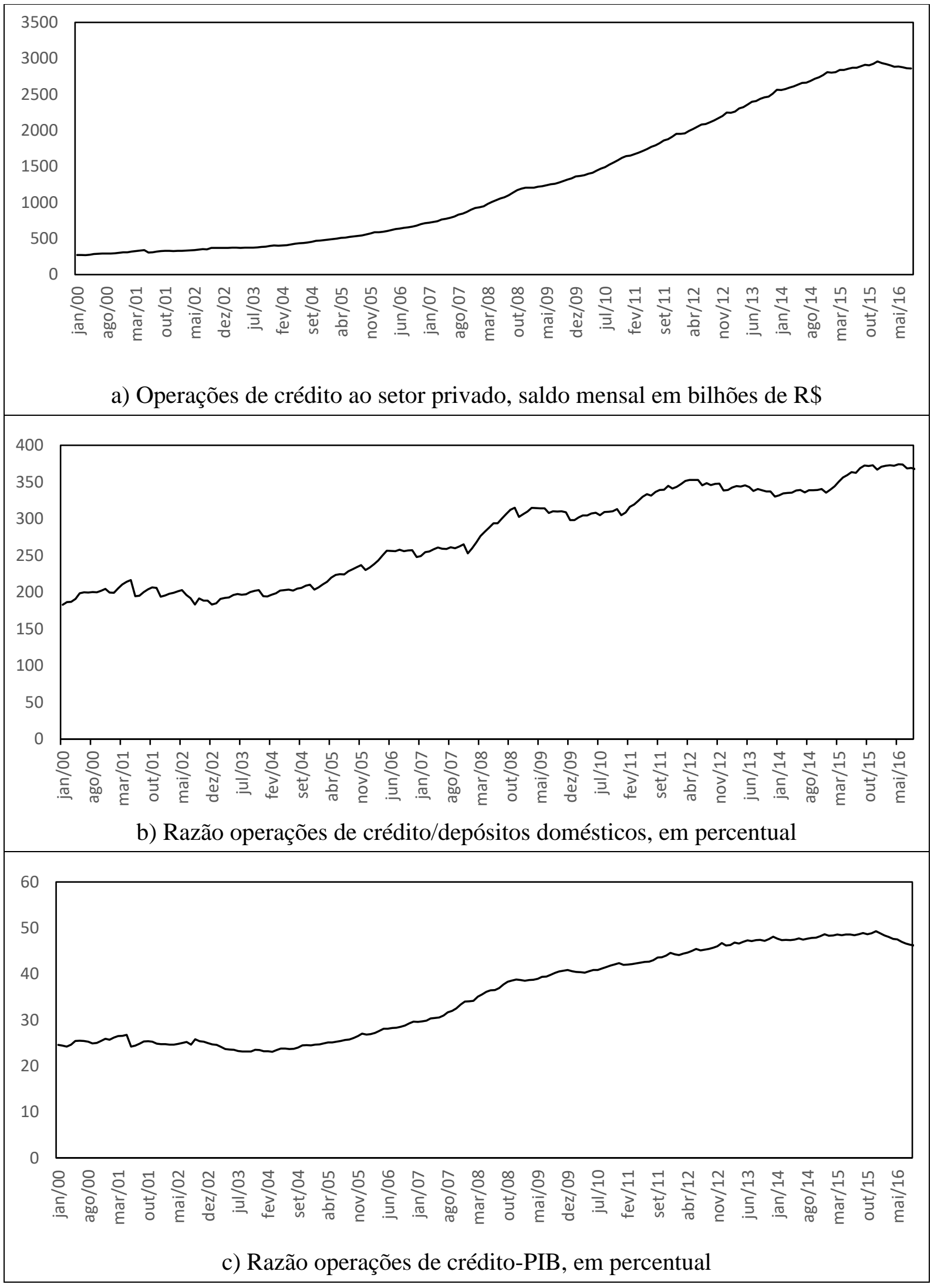

Fonte: elaboração própria com dados do Bacen. 
A relação percentual entre as operações de crédito e o volume de depósitos bancários está apresentada na Figura 1b, em que também é verificada tendência de crescimento dessa razão, ou seja, um aumento relativo das operações de crédito frente aos depósitos domésticos. O mesmo pode ser visto na Figura 1c, em que houve expansão da relação crédito-PIB, chegando a 50\% em fevereiro de 2016, apesar de exibir queda até meados de 2004, devido ao crescimento do PIB e à relativa estabilidade das operações de crédito neste período.

Em De Bonis e Stacchini (2010), a relação crédito-PIB era de 46\%, 77\% e 100\% nos EUA, França e Alemanha, respectivamente, em 2004, sendo que, segundo Assefa (2014), para o relatório da economia global esse valor deve ser superior a $70 \%$ num país com sistema financeiro bem desenvolvido. Assim, apesar do Brasil estar abaixo do valor considerado ideal, verifica-se que estava numa tendência ascendente, mesmo seu sistema financeiro não se caracterizando como bem desenvolvido.

Na Figura 2 é apresentada a evolução das seis séries temporais consideradas como determinantes dos empréstimos bancários. É possível verificar que de maneira geral os depósitos domésticos e o PIB apresentaram tendência de alta. Contudo, a partir de maio de 2014 os depósitos mudaram a sua trajetória, o que pode ser explicado pelo cenário de instabilidade econômica e política então apresentado no país.

Quanto às variáveis inflação e risco Brasil, é possível notar uma relativa tendência de estabilidade, com alguns pontos de pico e de vale. Dentre eles, destacam-se os meses referentes ao segundo semestre de 2002, quando ambas variáveis exibiram um valor muito acima do que vinham apresentando até então, sendo causado, principalmente, devido à eleição presidencial que se aproximava e também pelo “efeito Lula". Para Reinhart e Rogoff (2010, p. 53), a grave crise financeira do Brasil em 2002 foi deflagrada, em boa parte, pelas preocupações dos investidores com a mudança do governo centrista de Fernando Henrique Cardoso para a administração mais à esquerda do líder da oposição Luís Inácio Lula da Silva. A grande ironia, evidentemente, foi que o vitorioso com inclinações esquerdistas acabou sendo mais conservador na governança macroeconômica do que receavam os investidores ou, talvez, do que esperavam alguns de seus aliados, tendo como resultado, no momento posterior, a estabilidade das variáveis macroeconômicas aqui analisadas. 
Figura 2 - Determinantes do crédito, 2000-2016

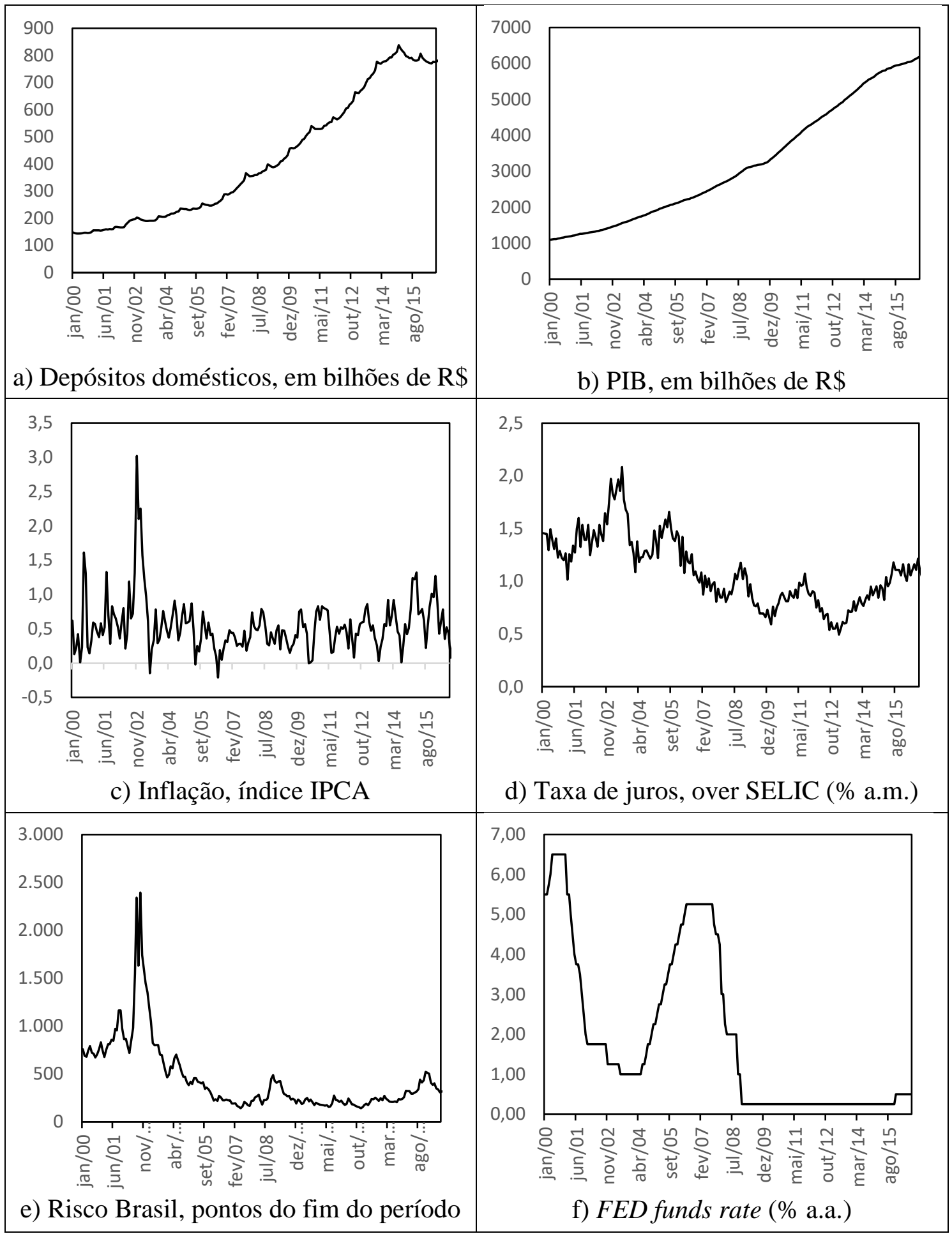

Fonte: elaboração própria com dados do Bacen, Ipeadata e Fed.

Ao analisar o comportamento da variável taxa de juros é possível verificar que, além da sua tendência em acompanhar os movimentos da inflação, devido ao regime monetário adotado, ela também apresenta alguns ciclos que coincidem com 
os ciclos eleitorais. Segundo Martins (2002), nas Teorias de Modelos de Ciclos Políticos, em períodos pré-eleitorais há uma redução no valor da taxa básica de juros, como forma de política monetária expansionista, sendo que nos períodos seguintes às eleições a SELIC volta a se elevar, como pode ser observado mais claramente nos anos de 2006, 2010 e 2014.

Com respeito à taxa de juros norte-americana é possível verificar que a mesma não é muito volátil ao longo do período analisado, mostrando assim certa rigidez na política monetária dos EUA. O último ciclo completo de aumento ocorreu de junho de 2004 até junho de 2006, quando passou de 1\% para 5,25\%, seguido por um ciclo de flexibilização da política monetária até o final de 2008, quando chegou a valores próximos de $0,25 \%$, valor este que permaneceu até 2016 , como reação à crise financeira iniciada em 2007.

\section{Resultados e discussões}

O objetivo principal deste estudo é verificar quais são os principais determinantes do crédito bancário ao setor privado, incluindo determinantes tanto de oferta quanto de demanda. Para tanto, o primeiro passo desenvolvido foi testar a estacionariedade das séries selecionadas, para que após tal etapa pudesse ser decidido qual método econométrico fosse aqui empregado. A Tabela 3 apresenta os testes realizados para verificar a presença de raiz unitária nas séries ${ }^{6}$.

Pelos testes realizados foi possível concluir que as variáveis crédito bancário ao setor privado, PIB, taxa de juros e depósitos bancários possuem raiz unitária em nível, sendo necessário trabalhar em suas primeiras diferenças para torná-las estacionárias. Por sua vez, o risco Brasil e a taxa de inflação são utilizadas em nível, já que ambas foram estacionárias nessa condição.

Assim sendo, tomando as variáveis estacionárias foi possível utilizar a metodologia VAR e realizar os testes para verificar qual seria a melhor defasagem (lag) para se estimar o modelo empírico. Feito isso, verificou-se que não houve um

\footnotetext{
${ }^{6}$ A sequência de testes realizada para verificar a estacionariedade das séries seguiu o proposto por Enders (2010, p. 208) e RAO (1994, p. 64-65). Assim, verificou-se primeiramente a estatística de teste com constante e tendência $\left(\tau_{\tau}\right)$, posteriormente, apenas com constante $\left(\tau_{\mu}\right)$ e, finalmente, sem constante e sem intercepto $(\tau)$. Além disso, seguindo a mesma sequência de estatísticas, na presença de autocorrelação foram incluídas as defasagens da variável dependente nas primeiras diferenças, com o teste Dickey-Fuller Aumentado (ADF). Ressalta-se que os testes ADF são indicados na presença de autocorrelação nos resíduos na estatística DF. Ademais, ainda foi incluída a estatística DF-GLS, proposta por Elliot, Rottemberg e Stock (1996), que é considerada mais robusta por superar problemas de baixa potência dos testes Dickey-Fuller.
} 
consenso entre os testes realizados acerca do melhor número de lags a ser considerado. Valendo-se da parcimônia e dos critérios de informação de Akaike (AIC), Bayesiano de Schwarz (SBIC) e de Hannan e Quinn (HQIC), optou-se por estimar utilizando uma defasagem.

Tabela 3 - Síntese dos testes de raiz unitária, Brasil, 2000-2016

\begin{tabular}{l|cccc|cccc|c}
\hline \multirow{2}{*}{ Variáveis } & \multicolumn{4}{|c|}{ Em nível } & \multicolumn{3}{|c|}{ Nas primeiras diferenças $(\Delta)$} & \multirow{2}{*}{ Ordem } \\
\cline { 2 - 8 } & $\mathbf{D W}$ & DF & ADF & DF-GLS & $\boldsymbol{D W}$ & DF & ADF & DF-GLS & \\
\hline Crédito & $1,27^{* *}$ & $-3,66^{* *}$ & $-3,78^{* * * *}$ & $-3,11$ & 2,08 & $-9,13^{* * *}$ & 1,41 & $-0,78$ & $\mathrm{I}(1)$ \\
PIB & $0,55^{* *}$ & $-4,76^{* * *}$ & $-2,02$ & $-1,10$ & $2,46^{* *}$ & $-5,28^{* * *}$ & $-3,62$ & $-2,62^{*}$ & $\mathrm{I}(1)$ \\
Risco & $2,42^{* *}$ & $-2,80^{*}$ & $-3,60^{* * *}$ & $-3,58^{* *}$ & $1,87^{a}$ & $-18,39^{* * *}$ & $-6,35^{* * *}$ & $-5,85^{* * *}$ & $\mathrm{I}(0)$ \\
Juros & $2,81^{* *}$ & $-3,37^{*}$ & $-0,50$ & $-1,92$ & 2,21 & $-24,44^{* * *}$ & $-4,78^{* * *}$ & $-4,54^{* * *}$ & $\mathrm{I}(1)$ \\
Depósito & $1,69^{a}$ & $-2,11$ & $-2,27$ & $-1,33$ & 2,01 & $-11,96^{* * *}$ & $-1,98$ & $-1,65$ & $\mathrm{I}(1)$ \\
Inflação & $1,86^{* *}$ & $-6,34^{* *}$ & $-6,35^{* * *}$ & $-6,29^{* * *}$ & 2,05 & $-15,42^{* * *}$ & $-5,38^{* * *}$ & $-1,83$ & $\mathrm{I}(0)$ \\
\hline
\end{tabular}

Fonte: estimativas do autor. Nota: Os asteriscos ${ }^{* * *},{ }^{* *} \mathrm{e}^{*}$ indicam que se rejeita a hipótese nula, com $1 \%, 5 \%$ e $10 \%$ de nível de significância respectivamente. ${ }^{a} \mathrm{O}$ Teste de Durbin Watson $(D W)$ é inconclusivo.

Considerando o modelo empírico proposto, são estimadas duas especificações, conforme a Tabela 4. Na primeira, com todas as variáveis explicativas e na segunda excluindo a variável representativa da taxa de juros norte-americana, pois não foi estatisticamente significativa na primeira especificação. O modelo clássico de regressão linear foi estimado apenas para fins de comparação com o modelo considerado como de melhor ajustamento

No modelo MQO, das variáveis consideradas como determinantes do crédito bancário, apenas os depósitos domésticos, PIB e o risco Brasil foram estatisticamente significativos, sendo que depósitos e PIB impactam de forma positiva o crédito bancário e o risco Brasil de forma negativa. Considerando a segunda especificação, no modelo de Vetor Autoregressivo é possível verificar que todas as variáveis foram estatisticamente significativas, ou seja, as diferentes variáveis em t-1 impactam as operações de crédito bancário em $t$.

Risco Brasil, inflação e taxa de juros defasados afetam de forma negativa o crédito bancário presente, conforme esperado, segundo a teoria econômica. No caso do Risco Brasil a justificativa para tal resultado consiste no fato de que um aumento da insegurança no cenário econômico do país tem como consequência uma retração da oferta de crédito por parte dos bancos. Um aumento do nível geral 
de preços reduz a oferta de crédito bancário, já que tem como consequência a redução do crescimento do crédito real, além de a inflação ser considerada como um indicador de confiança do ambiente macroeconômico. Assim, sua elevação, ou até mesmo a expectativa de piora, aumenta insegurança e a incerteza, reduzindo a demanda por crédito e, consequentemente, a sua taxa de crescimento.

Por fim, a taxa de juros impacta negativamente o crédito pelo simples fato de elevar o custo da obtenção dos empréstimos, ficando assim mais caro para o emprestador obter recursos.

Tabela 4 - Determinantes do crédito, Brasil, 2000-2016

\begin{tabular}{|c|c|c|c|c|}
\hline \multirow{3}{*}{ Variável } & \multicolumn{4}{|c|}{ Coeficientes } \\
\hline & \multicolumn{2}{|c|}{ Especificação 1} & \multicolumn{2}{|c|}{ Especificação 2} \\
\hline & MQO & VAR (1) & MQO & VAR (1) \\
\hline CRED & & $\begin{array}{c}0,322^{* * * *} \\
(0,077)\end{array}$ & & $\begin{array}{c}0,323^{* * *} \\
(0,077)\end{array}$ \\
\hline$D E P$ & $\begin{array}{c}0,829^{* * * *} \\
(0,104)\end{array}$ & $\begin{array}{c}-0,455^{* * * *} \\
(0,128)\end{array}$ & $\begin{array}{c}0,8304^{* * * *} \\
(0,104)\end{array}$ & $\begin{array}{c}-0,456^{* * * *} \\
(0,128)\end{array}$ \\
\hline$P I B$ & $\begin{array}{c}0,403^{* * *} \\
(0,066)\end{array}$ & $\begin{array}{c}0,388^{* * *} \\
(0,077)\end{array}$ & $\begin{array}{c}0,405^{* * * *} \\
(0,065)\end{array}$ & $\begin{array}{c}0,388^{* * *} \\
(0,077)\end{array}$ \\
\hline SELIC & $\begin{array}{c}-5109,622 \\
(5.792,963)\end{array}$ & $\begin{array}{c}-14.797,130^{* * *} \\
(6.212,932)\end{array}$ & $\begin{array}{l}-5.160,271 \\
(5.786,277)\end{array}$ & $\begin{array}{r}-14.808,340^{* * *} \\
(6.213,525)\end{array}$ \\
\hline$I P C A$ & $\begin{array}{l}-1.114,610 \\
(1.974,417)\end{array}$ & $\begin{array}{l}-3.605,178^{*} \\
(6.212,932)\end{array}$ & $\begin{array}{l}-1.070,294 \\
(1.971,411)\end{array}$ & $\begin{array}{l}-3.590,140^{*} \\
(2.111,222)\end{array}$ \\
\hline RISCO & $\begin{array}{c}-5,003^{* *} \\
(2,435)\end{array}$ & $\begin{array}{l}-4,637^{*} \\
(2,629)\end{array}$ & $\begin{array}{l}-4.798^{* *} \\
(2,417)\end{array}$ & $\begin{array}{l}-4,568^{*} \\
(2,612)\end{array}$ \\
\hline FED & $\begin{array}{l}-2.522,572 \\
(3.312,056)\end{array}$ & $\begin{array}{c}-796,740 \\
(3.543,184)\end{array}$ & & \\
\hline Constante & $\begin{array}{c}2.883,205 \\
(2.416,249)\end{array}$ & $\begin{array}{l}4.427,944^{*} \\
(2.591,413)\end{array}$ & $\begin{array}{c}2.786,603 \\
(2.410,291)\end{array}$ & $\begin{array}{l}4.394,760^{*} \\
(2.587,538)\end{array}$ \\
\hline $\mathrm{R}^{2}$ & 0,5212 & 0,4344 & 0.5192 & 0,4334 \\
\hline Observações & 199 & 198 & 199 & 198 \\
\hline
\end{tabular}

Fonte: estimativas do autor. Nota: desvio padrão entre parênteses. ${ }^{* * *}$ Nível de significância de $1 \% ;{ }^{* *}$ nível de significância de 5\%; ${ }^{*}$ nível de significância de $10 \%$.

O PIB e o próprio crédito bancário, em sua primeira defasagem, impactam de forma positiva a oferta de crédito no período subsequente. $\mathrm{O}$ crescimento econômico afeta o volume de crédito por dois canais, seja pelo aumento do consumo seja pelo aumento do investimento. No primeiro caso, há um aumento dos empréstimos para que os agentes elevem seu nível de consumo; no segundo, os empréstimos são realizados com o objetivo de investimento, principalmente em 
capital físico, sendo que em ambos os casos há uma relação positiva entre crédito e crescimento econômico. No que diz respeito ao próprio crédito, é possível verificar que tal variável é inercial, já que uma elevação no período anterior tem como consequência um aumento no período presente.

Um resultado que vai contra o que era inicialmente esperado diz respeito à variável depósitos domésticos. Aqui, o sinal obtido foi negativo, indicando que um maior depósito em $t-1$ implica em uma menor oferta de crédito em $t$. Uma justificativa para tanto decorre do fato da forte correlação entre depósitos domésticos e crédito bancário, sendo que ao inserir o crédito bancário defasado na estimativa do modelo VAR, tal variável absorve o efeito dos depósitos, ficando este parâmetro com o sinal negativo.

Após realizadas as estimativas, foram feitos os testes para verificar a validade do modelo ajustado. Assim, testou-se se todas as raízes se encontravam dentro do círculo unitário, tendo sido satisfeita tal propriedade, o que possibilitou realizar previsões. Para verificar o desempenho isolado das variáveis diante de algum choque nas inovações ou resíduos do modelo valeu-se da ferramenta da função de impulso-resposta, apresentada na Figura 3.

Os resultados apresentados indicam estabilidade do modelo, pois em todos os casos de choque nas variáveis determinantes, no longo prazo, a variável representativa dos empréstimos tende ao valor original. Um choque nos depósitos domésticos, em um primeiro momento gera uma redução das operações de crédito, sendo que no instante seguinte já há uma rápida tendência de estabilização, dado que no terceiro período após o choque inicial a variável dependente praticamente já retornou ao seu equilíbrio.

No caso da variável PIB, um choque tem como efeito inicial uma elevação nas operações de crédito, sendo que na sequência há uma convergência ao valor de longo prazo, dado o intervalo de confiança considerado, porém com uma relativa lentidão. Já um choque na taxa de juros tem um efeito inicial negativo sobre a concessão de empréstimos bancários, seguido por uma alternância entre positivo e negativo até atingir a estabilidade a partir do décimo período, quando o valor das operações de crédito atinge o equilíbrio de longo prazo.

O impulso na inflação tem como resposta, no primeiro momento, uma redução nas operações de crédito, sendo que no momento seguinte há um aumento acima do equilíbrio. Assim, no momento subsequente há uma tendência de queda 
em direção ao valor de longo prazo. Por fim, a variável risco Brasil é a que apresenta o ajustamento mais lento das consideradas no modelo. Aqui, seu impulso tem como resposta, no período inicial, uma queda nos empréstimos bancários. Posteriormente, essa redução tende ao valor de longo prazo, porém de forma mais lenta, de forma que, dado o intervalo de confiança considerado, o crédito bancário retorna ao seu equilíbrio.

Figura 3 - Resultado das funções de impulso resposta, Brasil, 2000-2016

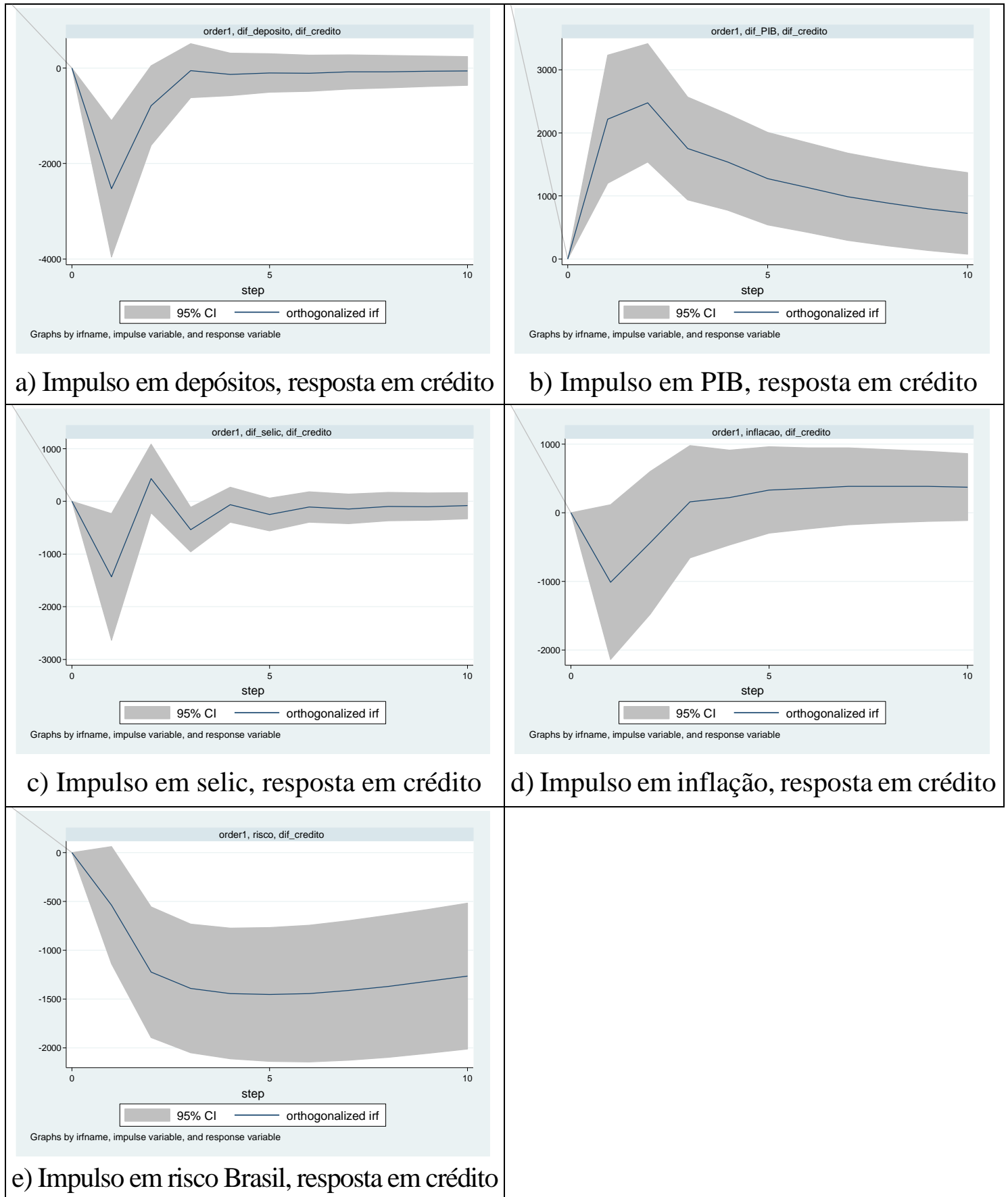

Fonte: estimativas do autor. 
Por fim, buscando verificar a contribuição de cada determinante do crédito bancário ao longo dos anos, foi realizada sua decomposição valendo-se dos coeficientes estimados no modelo MQO da especificação 2. Como pode ser observado na Figura 4, este cálculo foi realizado para o período total compreendido neste trabalho, bem como para cada ano, individualmente, objetivando analisar se houve alterações relevantes ao longo dos anos acerca da composição do crédito quanto aos determinantes.

\section{Figura 4 - Composição do crédito bancário, em percentual, 2000-2016}

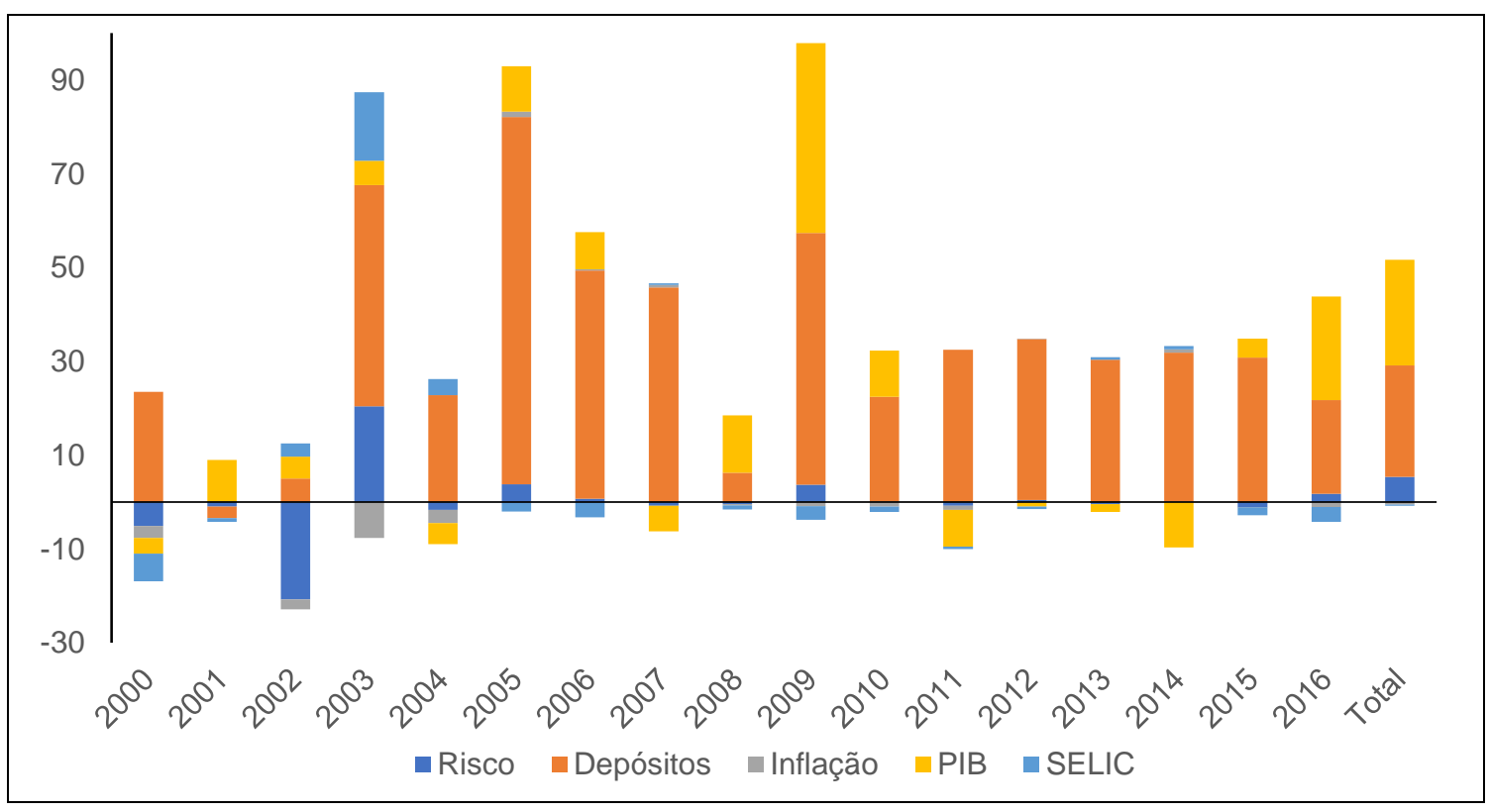

Fonte: estimativas do autor.

Ao longo dos anos, é possível destacar as parcelas relativas aos depósitos e ao PIB que, com algumas exceções, apresentaram as maiores proporções na composição dos determinantes do crédito, de modo que ambos contribuíram, em praticamente todo o período, positivamente. Ainda, a variável risco Brasil se mostrava como um determinante de grande destaque até o ano de 2003, deixando de assim ser a partir de então, conforme o cenário nacional se mostrava mais estável. Ademais, ao analisar o período completo, observa-se que a ordem de importância relativa na composição do crédito bancário consiste nos depósitos, PIB, risco Brasil, inflação e SELIC, do determinante com maior parcela para o com menor.

As relações até aqui apresentadas sugerem que o próprio crédito bancário e o crescimento econômico impactam positivamente no crescimento do crédito e, por 
outro lado, depósitos domésticos, taxa de juros doméstica, inflação, Risco Brasil e a taxa de juros norte-americana tem efeitos negativos. Estes resultados, com exceção dos depósitos, estão de acordo com diversos trabalhos empíricos, dentre os quais se destacam Almeida e Divino (2016), Mendonça e Sachsida (2013), Guo e Stepanyan (2011), Albulescu (2009), Fucidji e Prince (2009), Fritzer e Reiss (2008), Cottarelli et al. (2003), Calza et al. (2001 e 2003) e Hoffman (2001).

\section{Considerações finais}

O objetivo deste estudo foi verificar os principais determinantes da concessão de crédito bancário no Brasil, independentemente de ser considerado como variável do lado da oferta ou da demanda dos empréstimos. Dentro das variáveis inicialmente consideradas como importantes para a oferta do crédito, segundo a revisão da literatura realizada, apenas a que representa a taxa de juros externa (aqui considerado como a taxa do Federal Funds norte-americana) não foi estatisticamente significativa, considerando como determinantes da concessão de empréstimos os depósitos domésticos, o PIB, a taxa de juros, a inflação, o risco Brasil e o próprio crédito bancário.

Dentre os resultados obtidos, o destaque está para o impacto negativo que os depósitos, a taxa de juros, a taxa de inflação e o risco Brasil, todos em suas primeiras defasagens, causam sobre o crédito; já o crédito e o PIB, também em suas primeiras defasagens, geram um efeito positivo sobre os empréstimos.

Pode ser verificado ainda que o período de tempo para que o choque isolado em certo determinante do crédito se dissipe varia muito, sendo que a variável risco Brasil foi a que apresentou a maior lentidão. Apesar disso, verificou-se que o modelo apresentou considerável estabilidade, posto que o teste para verificar se o modelo apresentava raiz unitária foi satisfatório, confirmando assim que, no longo prazo, o modelo tende ao equilíbrio.

É possível concluir que políticas direcionadas ao setor financeiro capazes de estimular o financiamento do setor bancário e limitar os empréstimos inadimplentes continuam sendo essenciais para o crescimento sustentável do crédito no Brasil. Dessa forma, legislação na direção de fortalecer os direitos dos credores junto aos devedores, objetivando minimizar as perdas dos ativos bancários, mostram-se necessárias para que continue havendo expansão do desenvolvimento financeiro. Da mesma forma, emerge como essencial reduzir as 
oscilações macroeconômicas, em especial as que se refletem no indicador Risco Brasil, para que o país tenha a continuidade no processo de ampliação da disponibilidade de crédito para suas famílias e empresas, fator fundamental para um desenvolvimento sustentável de longo prazo.

\section{Referências}

ALBULESCU, C. T. Forecasting credit growth rate in Romania: from credit boom to credit crunch? Munich Personal RePEc Archive, MPRA Paper n. 16740, 2009.

ALMEIDA, F. D.; DIVINO, J. A. Determinantes do Crédito Bancário no Brasil: Uma Análise de Fatores Micro e Macroeconômicos. In: XLIV Encontro Nacional de Economia da ANPEC, 2016, Foz do Iguaçu. Anais do XLIV Encontro Nacional de Economia da ANPEC, 2016. p. 1-20.

ANGELONI, I.; KASHYAP, A. K.; MOJON, B. Monetary policy transmission in the euro area: a study by the eurosystem monetary transmission network. Cambridge University Press, 2003.

ASSEFA, M. Determinants of Growth in Bank Credit to the Private Sector in Ethiopia: A Supply Side Approach. Research Journal of Finance and Accounting, v. 5, n. 17, 2014.

BCB (Banco Central do Brasil). Sistema Financeiro Nacional. Disponível em: $<$ http://www.bcb.gov.br> Acesso em mar/2017.

BCE (European Central Bank). Long-term developments in MFI loans to households in the euro area: main patterns and determinants, Monthly Bulletin, out. 2007.

CALZA, A.; GARTNER, C; SOUSA, J. Modelling the demand for loans to the private sector in the Euro area. ECB Working Paper Series, n. 55, 2001.

CALZA, A.; MANRIQUE, M; SOUSA, J. Aggregate loans to the Euro Area private sector. ECB Working Papers Series, n. 202, 2003.

CASTRO, G; SANTOS, C. Determinantes das taxas de juro e do crédito bancário. Boletim Económico, primavera 2010.

COTTARELLI, C.; DELL'ARICCIA, G.; VLADKOVA-HOLLAR, I. Early Birds, Late Risers, and Sleeping Beauties: Bank Credit Growth to the Private Sector in Central and Eastern Europe and the Balkans. IMF Working Paper, n. 03/213, nov. 2003 
DE BONIS, R.; STACCHIN, M. What Determines the Size of Bank Loans in Industrialized Countries? The Role of Government Debt. Working Papers n. 9, Money and Finance Research Group, 2010.

DURBIN, J.; WATSON, G. S. Testing for serial correlation in least squares regression. II. Biometrika, v. 38, n. 1/2, p. 159-177, 1951.

ENDERS, W. Applied Econometric Time Series. Wiley, 2010.

FASE, M. M. G. The demand for commercial bank loans and the lending rate. European Economic Review, Maastricht, v. 39, n. 1, p. 99-115. 1995.

FED (Federal Reserve). Board of Governors of the Federal Reserve System. Disponível em: <https://www.federalreserve.gov/datadownload/Build.aspx?rel=H15> Acesso em fev/2017.

FRITZER, F.; REISS, L. An analysis of credit to the household sector in Austria. Oesterreichische Nationalbank Financial Stability Report, n. 16, p. 122-34, 2008.

FUCIDJI, J. R.; PRINCE, D. D. Determinantes do Crédito Bancário: uma Análise com Dados em Painel para as Maiores Instituições. Análise Econômica, p. 233$251,2009$.

GIMENO, R.; MARTINEZ-CARRASCAL, C. The interaction between house prices and loans for house purchase. The Spanish case. Working Paper 0605, Banco de España, 2006.

GREENE, W. H. Econometric analysis. Pearson Education International Edition, 2011.

GUO, K.; STEPANAYAN, V. Determinants of Bank Credit in Emerging Market Economies. IMF Working Paper WP/11/51, 2011.

HARBO HANSEN, N. J.; SULLA, O. Credit Growth in Latin America: Financial Development or Credit Boom? IMF Working Paper WP/13/106, 2013.

HOFMANN, B. The determinants of private sector credit in industrialized countries: do property prices matter? BIS Working Papers n. 108, 2001.

IMRAN, K.; NISHAT, M. Determinants of bank credit in Pakistan: A supply side approach. Economic Modelling, v. 35, p. 384-390, 2013.

IPEADATA (Instituto de Pesquisa Econômica Aplicada). Ipeadata macroeconômico. Disponível em: <http://www.ipeadata.gov.br/Default.aspx> Acesso em mar/2017. 
KAKES, J. Monetary transmission in Europe: the role of financial markets and credit. Edward Elgar Publishing, 2000.

KING, R. G.; LEVINE, R. Finance and growth: Schumpeter might be right. The quarterly journal of economics, v. 108, n. 3, p. 717-737, 1993.

LEVINE, R. Financial Development and Economic Growth: Views and Agenda. Journal of Economic Literature, v. 35, n. 2, p. 688-726, 1997.

LOWN, C.; MORGAN, D. P. The credit cycle and the business cycle: new findings using the loan officer opinion survey. Journal of Money, Credit and Banking, v. 38 , n. 6, p. 1575-1597, 2006.

MARTINS, R. C. de A. As teorias de ciclos políticos e o caso português. Grupo de Estudos Monetários e Financeiros (GEMF), n. 5, Faculdade de Economia da Universidade de Coimbra. 2002.

MENDONÇA, M. J.; SACHSIDA, A. Identificando a demanda e a oferta de crédito bancário no Brasil. Texto para Discussão 1837. Rio de Janeiro, IPEA, 2013.

RAJAN, R. G.; ZINGALES, L. Financial Dependence and Growth. The American Economic Review, v. 88, n. 3, p. 559-586, 1998.

REINHART, C. M.; ROGOFF, K. S. Oito Séculos de Delírios Financeiros: desta vez é diferente. Editora Campus, Rio de Janeiro, 2010.

SCHUMPETER, J. A. A Teoria do Desenvolvimento Econômico: uma investigação sobre lucros, capital, crédito, juro e o ciclo económico. São Paulo: Editora Abril, 1997.

SHIJAKU, G.; KALLUCI, I. Determinants of Bank Credit to the Private Sector: The Case of Albania. Bank of Albania Working paper, v. 48, n. 09, 2013.

SILVA, T. L. F. de; MORAES, G. I. de. Determinantes da demanda por crédito pessoa física-recursos livres, no período 2004-2011, em estados selecionados. Pesquisa \& Debate, 2013.

SIMS, C. A. Macroeconomics and reality. Econometrica, p. 1-48, 1980. 